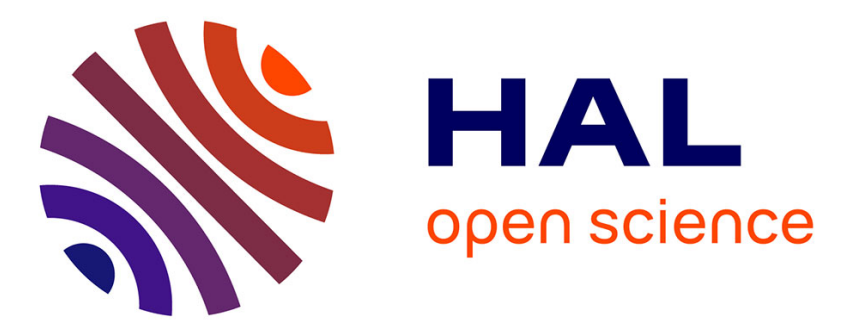

\title{
Carbon isotope discrimination as a surrogate for soil available water capacity in rainfed areas: A study in the Languedoc vineyard plain
}

Guillaume Coulouma, Laurent Prevot, Philippe Lagacherie

\section{- To cite this version:}

Guillaume Coulouma, Laurent Prevot, Philippe Lagacherie. Carbon isotope discrimination as a surrogate for soil available water capacity in rainfed areas: A study in the Languedoc vineyard plain. Geoderma, 2020, 362, 10.1016/j.geoderma.2019.114121 . hal-02968500

\section{HAL Id: hal-02968500 \\ https: / hal.inrae.fr/hal-02968500}

Submitted on 21 Dec 2021

HAL is a multi-disciplinary open access archive for the deposit and dissemination of scientific research documents, whether they are published or not. The documents may come from teaching and research institutions in France or abroad, or from public or private research centers.
L'archive ouverte pluridisciplinaire HAL, est destinée au dépôt et à la diffusion de documents scientifiques de niveau recherche, publiés ou non, émanant des établissements d'enseignement et de recherche français ou étrangers, des laboratoires publics ou privés.

\section{(ㄷ)(1) $\$$}

Distributed under a Creative Commons Attribution - NonCommercial| 4.0 International 


\section{Carbon isotope discrimination as a surrogate for}

\section{Soil Available Water Capacity in rainfed areas: A study in the Languedoc Vineyard plain}

Guillaume Coulouma*, Laurent Prevot, Philippe Lagacherie

LISAH, Univ Montpellier, IRD, INRA, SupAgro, F-34060 Montpellier, France

${ }^{*}$ corresponding author

\section{Highlights}

Four contrasting years were monitored to investigate different soil water conditions.

The Soil Available Water Capacity (SAWC) was measured on 21 sites.

The integrated relationship between the mean of $\delta^{13} \mathrm{C}$ and SAWC was successfully tested. $\delta^{13} \mathrm{C}$ of grapes can be considered as a simple and inexpensive surrogate for determining SAWC.

16

\section{Abstract}

Soil available water capacity (SAWC) is a key soil function for plant growth. Classical SAWC characterization requires time consuming determinations of bulk density and specific soil moisture contents. Consequently, these data are extremely sparse in existing soil databases. Using surrogates of the vegetal response to characterize SAWC across a great number of sites constitutes a promising perspective. The carbon isotope ratio $\left(\delta^{13} \mathrm{C}\right)$ measured in a plant organ is largely known as an indicator of plant water status. The aim of the paper is to test $\delta^{13} \mathrm{C}$ as an indicator of SAWC in rainfed vineyard.

$\delta^{13} \mathrm{C}$ values of grapes at harvest time were measured at 21 sites on the Languedoc vineyard plain with contrasting SAWC (33 to $308 \mathrm{~mm}$ ) for four years (2015 to 2018) with contrasting annual precipitation (from 390 to $715 \mathrm{~mm}$ ). The relationships between $\delta^{13} \mathrm{C}$ and SAWC 
determined using a classical approach (soil description, soil sampling and laboratory methods) were satisfactory for all years (RMSEs from cross validation were between 35 and $61 \mathrm{~mm}$ ). Better relationships were obtained between $\delta^{13} \mathrm{C}$ and SAWC for years that showed a full winter recharge of SAWC $\left(2015,2017\right.$ and 2018). Averaging the $\delta^{13} \mathrm{C}$ measurements over such years provided an even better relationship ( $R^{2}=0.85$; RMSE $\left.32 \mathrm{~mm}\right)$, which was successfully validated in distant sites on the Languedoc vineyard plain.

This work demonstrated that $\delta^{13} \mathrm{C}$ can be considered as a simple and inexpensive surrogate for estimating SAWC. In addition to considerably increasing the density of SAWC measurements, the use of $\delta^{13} \mathrm{C}$ would lead to better consideration of the contribution of deep horizons in the case of perennial plants. Application of this isotopic technique to other agrosystems is required to better define the potential areas of use of $\delta^{13} \mathrm{C}$.

\section{Introduction}

Soil available water capacity (SAWC) or soil available water holding capacity (AWHC) is a well-known concept that has been used for a long time to express the capacity of soils to store water for plants (Veihmayer and Hendrickson, 1927). It has been demonstrated that SAWC is one of the most important soil factors for plant growth and that it influences photosynthesis rate, carbon allocation, and nutrient cycling (Lebourgeois et al., 2005; Breda et al., 2006). It is therefore a first order parameter that is used in crop modelling (Brisson et al., 1998), land evaluation and, recently, soil ecosystem service assessment (Dominati et al. 2014).

53 Determining the SAWC requires costly and time-consuming measurements of soil properties.

54 Bulk density and volumetric water content at wilting point and field capacity require 55 undisturbed sampling and physical measurements in the laboratory (Klute, 1986; Bruand and 56 Tessier, 2000). Moreover, determination of the SAWC for perennial plants having a deep root 
system requires investigation of the deep horizons, which are not always accessible. Consequently, the SAWC data are extremely sparse in existing soil databases, which prevents the use of these databases as inputs for Digital Soil Mapping approaches (McBratney et al., 2003) as is currently done for other more current soil properties (e.g., Organic Carbon, textural fractions). To overcome this problem, pedotransfer functions (Rawls et al., 1982; Al Majou et al., 2008) can be used to estimate the specific water content from available soil properties, which has allowed the production of SAWC maps (Leenaars et al., 2018, Dobarco et al., 2019). However, these functions convey a great amount of uncertainty that could generate significant errors in SAWC maps (Dobarco et al., 2019). Therefore, the increase in well-characterized sites with regard to SAWC is a prerequisite for a significant improvement of SAWC maps.

Using surrogates of the vegetal response to characterize SAWC across a great number of sites is a promising perspective. Remote sensing approaches that involve vegetation indices have been proposed. For example, Araya et al. (2016) proposed to directly test the multidate Normalized Difference Vegetation Index as a surrogate for the dynamic response of plants to soil functions, especially SAWC. A relationship between evapotranspiration-based covariates extracted from ASTER satellite imagery and soil depth, a first order parameter for SAWC calculation, was found in vineyards (Taylor et al., 2013).

In the same way, the carbon isotope ratio $\left(\delta^{13} \mathrm{C}\right)$ is largely known as an indicator of plant water status and has been tested on different species such as wheat (Merah et al., 2001), conifers (Warren et al., 2001), and vineyards (Gaudillère et al., 2002). In the case of vineyards, many studies have demonstrated the linear relationships between $\delta^{13} \mathrm{C}$ measured in berries at harvest and the minimal values of pre-dawn leaf water potential during ripening. Van Leeuwen et al. (2001) measured the $\delta^{13} \mathrm{C}$ in berries from 9 closed vineyards with 81 different soils during contrasted years. They found a linear relationship between $\delta^{13} \mathrm{C}$ and the 82 minimal values of pre-dawn leaf water potential during ripening $\left(R^{2}=0.81\right)$. The soils and the 83 years explained a large part of the variance. Gaudillère et al. (2002) found a linear 84 relationship in case of various grapevine genotype (e.g. Cabernet Sauvignon, Cabernet 
Franc and Merlot). They also tested 31 grapevine varieties within a same growing condition and they measured $\delta^{13} \mathrm{C}$ values from -21.6 (Riesling) to -24.9 (Muscat). However, 24 varieties ranged between -22.5 and -23.8. Gomez-Alonso and Garcia-Romero (2010) found lower differences between 8 varieties in a same growing condition, from -20.5 (Airen) to 21.6 (Sauvignon blanc). Santesteban et al. (2015) reviewed the $\delta^{13} \mathrm{C}$ datasets from the literature and proposed $\delta^{13} \mathrm{C}$ threshold values that correspond to significant differences in vineyard water status during the ripening period.

The low cost of $\delta^{13} \mathrm{C}$ measurements that allows the collection of large samplings was exploited in some studies. A large set of $\delta^{13} \mathrm{C}$ measurements was used to produce a spatial model of vine water status at the plot scale (Herrero-Langreo et al., 2013). Some studies focused on the use of $\delta^{13} \mathrm{C}$ as an indicator of functional parameters in relation to vine water status. Guix-Hebrard et al. (2007) used measured $\delta^{13} \mathrm{C}$ for revealing the influence of water table depth on the grape maturation. Van Leeuwen et al. (2018) considered $\delta^{13} \mathrm{C}$ as a highresolution tool among a set of indicators for characterizing vineyard terroirs. Costantini et al. (2010) delineated the Sangiovese terroir with a combination of proximal soil sensing and the measurement of $\delta^{13} \mathrm{C}$ in Sangiovese wines. However, to our knowledge, $\delta^{13} \mathrm{C}$ measurements have still not been correlated with SAWC measurements. The vine water status via the predawn leaf water potential is known to be

103 correlated to the fraction of transpirable soil water (FTSW) (Pellegrino et al., 2004), which,

104 during the driest growing seasons, may be considered as a surrogate for SAWC in rainfed 105 areas. Therefore, a relationship between easily accessible $\delta^{13} \mathrm{C}$ measurement and the 106 SAWC is conceivable. Moreover, in the case of vineyards, the roots of grapevines are 107 generally established throughout the entire horizons of soils, except for the limiting specific 108 conditions (hydromorphic horizons, cemented horizons or $\mathrm{C}$ horizons with chemical or 109 physical limitations), despite the high dependence of grapevine rooting patterns on the 110 rootstock.

111 The aim of this paper is to directly test $\delta^{13} \mathrm{C}$ measured in vineyards at the harvest time as a 112 surrogate of a large range of measured SAWCs in different soils of the Languedoc area. 
113 Four years were monitored to investigate different soil water conditions during the growing

114 seasons of the vineyards.

2. Materials and methods

2.1Study areas

The 21 sites that constitute the experimental dataset of this study were located in two study

121 areas, both included in the vineyard plain of Languedoc in southern France (figure 1). The

122 first study area is the Peyne River catchment which includes 13 sites. The second one is

123 located near Narbonne close to the sea and includes 8 sites. The elevation ranges from $5 \mathrm{~m}$

124 (Pech Rouge) to 340 m (northwest of the Peyne area). The landscape has gentle landforms.

125 The grapevine varieties and the agricultural practices are representative of the region. The

126 precipitation conditions were monitored during 25 years both in the Peyne catchment and in

127 Pech Rouge station. The annual precipitation of $628 \mathrm{~mm}$ for the Peyne catchment and 562

$128 \mathrm{~mm}$ for the Pech Rouge station are unevenly distributed throughout the year, with major

129 precipitation occurring in autumn and spring. The annual reference evapotranspiration is

$1301109 \mathrm{~mm}$. The mean maximum temperature is approximately $15^{\circ} \mathrm{C}$ in January and $30^{\circ} \mathrm{C}$ in

131 July/August. The catchments present a typical Mediterranean hydrological response, with the

132 potential annual water storage mainly dependent on the annual precipitation and the

133 occurrence of extreme runoff events, which are not favourable for the water infiltration.

134 Therefore, the annual water balance highly varies between years.

135 The soil pattern of the Peyne catchment arises mainly from variations in lithology, and the 136 main soil characteristics depend on the type of parent material (figure 1). The entire valley is

137 underlain by heterogeneous Miocene marine calcareous sandstone and lacustrine limestone,

138 which form the parent material of several types of soil, including calcaric leptosols, calcaric 139 regosols, and calcisols (IUSS working group WRB, 2015). These Miocene sediments are 140 partly overlain by successive alluvial deposits ranging from Pliocene to Holocene, and they 
141 differ in their initial nature and in the duration of weathering conditions. Therefore, these

142 sediments have produced intricate soil patterns that include a great range of soil types such

143 as calcisols, endogleyic calcisols, luvisols (chromic), and fluvisols. Recent volcanic activity 144 and local transport of colluvium material along slopes have added to the complexity of the

145 soil pattern. Consequently, the soils of the valley present contrasting characteristics in terms 146 of texture, stoniness and soil depth, which determine their SAWC.

147 The second study area corresponds to the experimental station of INRA Pech Rouge located 148 in the "La Clape" massif, a small Pyrenean thrust sheet composed of Cretaceous marine 149 deposits. Contrasting sites were chosen among different available SAWCs. The main soils 150 were developed over interbedded micritic limestones and orbitolina clayey limestones. The 151 soils were generally thin over the limestones, with a high content of coarse fragments 152 (Leptosols). In the bottom part of the fields, there were important accumulations of 153 sediments, and the soil depth increased (Calcisols).

<Figure 1 here >

$157 \quad 2.2 S$ ite sampling

158 The sites were chosen to be representative of the diversity of soil characteristics, especially

159 soil depth and SAWC (table 1 and figure 1). A total of 13 sites were located in the Peyne

160 catchment to calibrate the relations, and 8 additional sites were located in the Pech Rouge 161 INRA station to validate the relations with independent sites. A site corresponds to 162 approximately $15 \mathrm{~m}^{2}$ (9 vines) within the vineyards to limit the spatial variability of soil 163 properties and assign a SAWC to a site with a maximum of precision. Regarding 164 agronomical aspects, the vineyards were chosen (i) to be representative of the regional 165 vineyards and (ii) to avoid the situations where the relation between the SAWC and the vine 166 water status may be disturbed (e.g., irrigated zones; young vineyards with insufficient root 167 systems). The vineyards were $15-20$ years old and without irrigation. The plantation density 168 (4000 plants/ha), the trellising (2 stages), the pruning system (double cordon) and the 
169 number of buds (16 to 20) were the same at all sites. However, the variety differed, with

170 Syrah (sites 6,9), Cabernet Sauvignon (sites 4,10,18), Sauvignon blanc (site 14), Grenache 171 noir (site 5,8), and Merlot (sites 2,3,7,11,12).

172

173 2.3Soil survey

174

175 Soil pits were dug near each selected site during the winter of 2016 and the soil 176 morphological parameters were observed in the field (soil depth, structure, colour, stones, 177 roots abundance) according to the guidelines for soil description (FAO, 2006). The soil 178 horizons were determined in relation to these descriptions, and bulk densities $\left(\rho_{\mathrm{b}}\right)$ were 179 measured by core sampling with $100 \mathrm{~cm}^{3}$ stainless-steel cylinders (Blake and Hartge, 1986)

180 with 6 replicates per horizon. $\rho_{b}$ was determined as the ratio between the dry soil mass and

181 the total core sampling volume. Moreover, each sample was sieved to extract the coarse 182 fragments (e.g. $>2 \mathrm{~mm}$ ), and the bulk density of the fine earth ( $\left.\rho_{\mathrm{bFE}}\right)$ was determined as the 183 ratio between the dry soil mass without the coarse fragments and the total core sampling 184 volume without the volume corresponding to the coarse fragments. This volume was 185 calculated from the mean bulk density of the coarse fragments ( $\rho_{b C F}$ ) according to the type of 186 pebbles already measured in the Peyne catchment and in Pech Rouge station (e.g. old 187 alluvial pebbles 2.8 and limestone 2.5). Undisturbed soil samples of over $500 \mathrm{~g}$ were taken in 188 each horizon for characterisation of the specific water retention at $-33 \mathrm{kPa}$ (field capacity) 189 and $-1500 \mathrm{kPa}$ (wilting point) according to the pressure chamber method (Klute, 1986).

190 Disturbed soil samples localized in the same horizons were used for classical texture and 191 coarse-fragment analysis. The samples were sieved to separate pebbles greater than $2 \mathrm{~mm}$ 192 in diameter from the fine earth. The particle size distribution was analysed following the 193 destruction of organic matter and dispersion with sodium hexametaphosphate (AFNOR, N

194 FX 31-107). The clay $(<2 \mu \mathrm{m})$ and silt $(2-50 \mu \mathrm{m})$ contents were quantified by sedimentation, 195 and sand $(50-2,000 \mu \mathrm{m})$ was measured via sieving. The detailed results of the soil survey are 196 summarized in Table 1. 
2.4Soil available water capacity (SAWC)

199

200 The SAWC of each horizon was calculated based on equation (1). The morphological 201 variables that impact the rooting were taken into account for the calculation of the actual 202 SAWC. In the case of low content of coarse fragments $(<10 \%)$, their contributions to the 203 SAWC were neglected. However, in the case of high content of coarse fragments (Pech 204 Rouge sites), additional SAWCs were calculated from the water content measured within the coarse fragments (Tetegan et al., 2011). Considering that the 15-20 year-old studied vineyards had sufficient time to develop their root system, horizons without living roots did not contribute to the SAWC. The different causes were examined. Site 2 presented a deep horizon $(1.95-2.70 \mathrm{~m})$ without roots due to (i) seasonal waterlogging within the horizon and (ii) vertic properties not suitable for roots. Site 4 presented a large soil depth but the deep horizons were temporary waterlogged, and no roots were observed. Horizon C of site 8 presented a high content of powder of calcium carbonate, and no roots were observed. The calculation of SAWC and general soil data are given in Table 1.

213

214

$$
S A W C=\sum_{\text {horizon }=1}^{n}\left(Z_{(\text {horizon })} \times(W s-W r) \times \rho \mathrm{bFE} \times\left\{10-\frac{C F \times \rho \mathrm{b}}{10 \times \rho_{b C F}}\right\}\right)
$$

\section{Where:}

SAWC (mm)

$\mathrm{n}$

$\mathbf{Z}_{\text {(horizon) }}(\mathrm{m})$

$W S$ *

$W r^{*}$

CF $(\%)^{*}$

$\rho_{\mathrm{b}} \quad *$

$\rho_{\text {bFE }}$

$\rho_{\mathrm{bCF}}$

total soil available water capacity

number of actual horizon

thickness of the horizon

mass water content at 0.33 bar

mass water content at 15 bar

mass proportion of coarse fragments

bulk density

bulk density of the fine earth

bulk density of coarse fragments

*each property was analysed for each actual horizon

$<$ Table 1 here> 
$2.5 \delta^{13} \mathrm{C}$ sampling and analysis

238 A total of 100 berries were collected at the harvest time from the 9 vines at each site during 4 successive years (2015- 2018) for the Peyne sites. The sampling dates varied between the

$24025^{\text {th }}$ August (2016), and the $10^{\text {th }}$ September (2015), depending on the vine variety and the 241 climate of the year. The samples for the Pech Rouge site were collected only in 2018. The 242 samples were ground at the laboratory, and $2 \mathrm{ml}$ samples were centrifuged and oven dried.

243 The resulting powder was analysed by a continuous-flow isotope ratio mass spectrometer 244 (ISOPRIME, GV Instruments, Manchester). $\delta^{13} \mathrm{C}$ values are expressed with reference to the 245 PeeDeeBelemnite (PDB) standard (Farquhar et al., 1989). In the case of grapevines,

246 Santesteban et al. (2015) proposed a correspondence between $\delta^{13} \mathrm{C}$ and the water deficit via 247 the vine water status measured in a set of studies. The water deficit is considered as weak or 248 null with $\delta^{13} \mathrm{C}$ lower than $-26 \%$; conversely, the water deficit is severe with a $\delta^{13} \mathrm{C}$ higher 249 than $-24 \%$.

\subsection{Experimental protocol}

252 The Peyne sites were first chosen to calibrate the relationship between $\delta^{13} \mathrm{C}$ and SAWC at 253 the site scale. The relationships were separately analysed for each successive year to 254 enable discussion of the results according to the specificity of each vintage. A classical 255 leave-one-out cross validation was applied to validate the relationship on the Peyne sites for 256 each year.

257 Three years $\left(2015,2017\right.$ and 2018) were chosen to calculate the $\delta^{13} \mathrm{C}$ mean for each site 258 within the Peyne catchment and calibrate a new multidate relationship between $\delta^{13} \mathrm{C}$ and 259 SAWC. This relationship was validated with the independent Pech Rouge sites using 260 classical figures-of-merit, coefficients of determination $\left(R^{2}\right)$ and Root Mean Square Errors 261 (RMSE). 


\section{Results}

\subsection{Precipitation}

266 The four years exhibited large variations of annual precipitation in the Peyne catchment 267 (figure 2). Only the 2015 precipitation was close to the 25 -year average precipitation. The 2682016 precipitation was largely below this average. 2017 and 2018 precipitations exceeded 269 the 25-year average precipitation. Although the 2017 growing season was the driest among 270 the four years, most of the 2017 precipitation events occurred before bud break and secured 271 the soil water storage. The precipitations during 2018 in Pech Rouge station were also upper

272 than the 25-year average precipitation.

273 <Figure 2 here>

276 The $\delta^{13} \mathrm{C}$ mean results from the Peyne site showed significant differences between years 277 (Table 2). The ranges of values are in accordance with those found by Guix et al. (2007) 278 within the same region. As expected, the driest year (2016) presented a significantly higher $279 \delta^{13} \mathrm{C}$ mean and the highest maximum value. However, the minimum value measured in 2016 was comparable to that in the other years. The years 2017 and 2018 had lower $\delta^{13} \mathrm{C}$ values.

281 The $\delta^{13} \mathrm{C}$ measured values in the Pech Rouge sites during 2018 were significantly higher 282 than those measured in the Peyne sites.

$284<$ Table 2 here>

\subsection{Relationship between $\delta^{13} \mathrm{C}$ and SAWC}

The linear relationships between SAWC and $\delta^{13} \mathrm{C}$ were significant for the Peyne sites regardless of years (Figure 3). The increase of $\delta^{13} \mathrm{C}$ always corresponded to a decrease of SAWC. Regarding the cross validation, the year 2015 presented the lowest errors of prediction, which were of the same order of magnitude as the errors of the local determinations of SAWC from field laboratory measurements. 
<Figure 3 here>

293 The errors were more important in 2017 and 2018, although the general trend was 294 conserved. Conversely, the relationship during the year 2016 was different. $\delta^{13} \mathrm{C}$ values 295 corresponding to sites with a medium SAWC (100 -200 mm) increased, particularly for sites $6,8,10,18$. The sites with high $(11,12)$ or low $(3,5)$ SAWC had a relative stability through the years. Regarding the trend of the relationship, the measured $\delta^{13} \mathrm{C}$ for site 5 was always lower than expected.

<Figure 4 here>

301

For each site, the means of $\delta^{13} \mathrm{C}$ measured during 2015, 2017 and 2018 were calculated and compared with the SAWCs (figure 4). The new calibration over the Peyne sites during the three years presented better figures of merit than each separated year. Moreover, the successful validation of this new relationship with additional independent sites (Pech Rouge) during 2018 confirmed the ability to predict SAWC from a punctual $\delta^{13} \mathrm{C}$ measurement. The RMSE decreased to $32 \mathrm{~mm}$ for the year 2018, which corresponds to satisfactory prediction. However, the predicted SAWC values larger than $100 \mathrm{~mm}$ were significantly higher than the measured ones.

\section{Discussion}

\subsection{Relationship between SAWC and vineyard water status}

314 The investigated situations were chosen to represent a large variety of soil depth and soil

315 characteristics in relation to the SAWC, including soils with shallow groundwater and different 316 rooting constraints, as reported by Leenaars et al. (2018). Despite these greatly different situations, satisfactory linear relationships were found between $\delta^{13} \mathrm{C}$ and SAWC during each 
318 year. These results are new. Previously, $\delta^{13} \mathrm{C}$ as a surrogate for the vineyard water status

319 was largely used to precisely determine soil-related terroir factors (van Leeuwen et al., 2009;

320 2018). The vineyard water status depends on the FTSW present within the rooted horizons.

321 During the driest growing seasons, the vineyard soil provides storage water in relation to its

322 SAWC, considered as the maximum stored water within the soil. Our results show a

323 relationship between the $\delta^{13} \mathrm{C}$ plant surrogate and the SAWC. The main hypothesis mainly

324 relates to the fact that vine roots infiltrate the horizons included with the SAWC calculation.

\subsection{Climatic determinant of the SAWC predictions}

327 The large variations of annual precipitation during the 4 years produced a variation of the 328 water supply during the growing season mainly via the soil water storage before bud break.

329 The 2016 precipitation was largely below the 25-year annual precipitation average, and the 330 water recharge before bud break can be considered incomplete. Conversely, the recharge 331 during the other years was higher and corresponded to at least $200 \mathrm{~mm}$.

332 Except for the year 2016, the trend of the relationship between $\delta^{13} \mathrm{C}$ and SAWC was conserved despite differences in precipitation that occurred during the growing season. The

334 linear relationships present a relative stability, particularly with extreme situations. Higher

335 SAWCs correspond to sites with sufficient water recharge to preserve a low vine water stress

336 during the ripening, regardless of year. Conversely, lower SAWCs correspond to sites with

337 shallow soils or soils with a rooting limit. The water recharge is not sufficient for the years, 338 and the sites always have high $\delta^{13} \mathrm{C}$ values. The variations between years are significant for 339 the sites with a medium SAWC and are more sensitive to precipitation during the summer 340 period. For example, site $7(121 \mathrm{~mm})$ provided a very low $\delta^{13} \mathrm{C}$ due to a storm event at the 341 beginning of August 2017. The year 2016 corresponds to a severe water deficit due to an 342 incomplete water recharge of the SAWC. Therefore, the relationship from the 2016 dataset 343 underestimates the SAWC. 
$346 \delta^{13} \mathrm{C}$ can be prone to variations across the different vine varieties, related to different

347 sensitivities to water stress (de Souza et al., 2005). In this case study, merging five different 348 vine varieties could constitute a disturbing effect. Indeed, the $\delta^{13} \mathrm{C}$ values measured in two 349 sites with the same SAWC but with a different variety do not precisely express the same 350 corresponding minimal values of pre-dawn leaf water potential. The specific driest year of 3512016 could also exacerbate the variations due to the variety (de Souza et al., 2005).

352 However, the impact of vine variety on the relation between $\delta^{13} \mathrm{C}$ and pre-dawn leaf water 353 potential could be strongly questioned. On one hand, the calibration of the linear relationship 354 for the same grapevine variety between $\delta^{13} \mathrm{C}$ and pre-dawn leaf water potential shows 355 relatively scattered data. For example, the linear relationship explained only $70 \%$ of the 356 variance in the case of the Tempranillo variety (Santesteban et al., 2012). Guix et al. (2007) 357 found only $80 \%$ of the explained variance for Syrah in the same Peyne valley. Additionally, 358 the relationship from four different varieties showed $95 \%$ of the explained variance 359 (Gaudillère et al., 2002). Gomez-Alonso and Garcia-Romero (2010) tested eight varieties in 360 the same site with the same soil conditions. The standard deviation of $\delta^{13} \mathrm{C}$ measurement 361 was only 0.7 . Restricting $\delta^{13} \mathrm{C}$ to a unique vine variety is therefore not recommended since 362 the added value to the $\delta^{13} \mathrm{C}$-SAWC relationship is far from being demonstrated, whereas it 363 may induce sampling difficulties related to the exclusive locations of each vine variety in 364 specific pedo-climatic situations.

\subsection{Added value of a multidate approach}

368 The climatic variability and intrinsic $\delta^{13} \mathrm{C}$ variations were combined with a relationship 369 between a mean of each annual measurement of $\delta^{13} \mathrm{C}$ and SAWC. The results outperformed 370 the relationships for each study year, excluding 2016. The relationships did not change for 371 the sites with extreme SAWC, high or low. Conversely, the $\delta^{13} \mathrm{C}$ mean for the site with 372 medium SAWC moderated the interannual variability. This integrated relationship was 
373 successfully tested for the independent Pech Rouge sites. The first analysis of figure 4 (right)

374 seems to show an overestimation of SAWC $>100 \mathrm{~mm}$. The measurement of SAWC in the

375 case of thin soils with high coarse fragment content and with cracked bedrock is 376 questionable. The contribution of coarse fragments to the water storage was included in the 377 SAWC. However, the measurements of specific water content in coarse fragments were 378 disturbed by the time of water extraction and pore connectivity. The lateral variability of 379 cracks is not visible with punctual pit observations, especially in thin soils over limestones. In 380 this specific case, $\delta^{13} \mathrm{C}$ probably constitutes a better integrated parameter to estimate the 381 real SAWC than the conventional SAWC measurement.

\subsection{Limitations and further approaches}

384 The study of four contrasted consecutive years shows that the use of the $\delta^{13} \mathrm{C}$ as a surrogate of SAWC is mainly dependent on the water recharge before bud break especially for the low SAWC. Furthermore, this surrogate cannot be applied in irrigated crops, which disconnect the SAWC and the water status of the plant. The importance of the climate-dependent water status argues for consolidating the relationships with additional study years with atypical water recharge, which was not monitored in this work. For example, a large amount of rain during the summer would dramatically decrease the $\delta^{13} \mathrm{C}$.

391 The distribution of SAWC for the Peyne sites had an effect on the relationships between

$392 \delta^{13} \mathrm{C}$ and SAWC. Only two sites presented a SAWC higher than $250 \mathrm{~mm}$, and the majority of

393 the Peyne sites had medium SAWC values between 100 and $200 \mathrm{~mm}$. The relationship was

394 more sensitive to extreme SAWC and future sites with lower SAWC and higher SAWC in the 395 Peyne catchment might ameliorate the genericity of the relationship. In the same way, the 396 validation in Pech Rouge suffered a lack of sites with high SAWC.

397 The relation between $\delta^{13} \mathrm{C}$ and SAWC was established in restricted crop situations, namely, 398 rainfed vineyards. $\delta^{13} \mathrm{C}$ variations on other plants than vineyards have been demonstrated to 399 be reliable to water stress. The present study could be extended to other land uses, with care 
400 in characterising the maximum rooting depth, which could induce underestimation of the 401 SAWC, particularly in the case of annual plants.

402 Beyond the above-evoked limitation, this work demonstrated that $\delta^{13} \mathrm{C}$ can be considered in 403 some particular landscapes as a simple and inexpensive surrogate for determining SAWC. It 404 could therefore be used in further digital soil mapping (DSM) approaches that deal with 405 SAWC as new soil input for calibrating or validating the DSM models. In addition to 406 considerably increasing the density of measurement, the use of $\delta^{13} \mathrm{C}$ would lead to better 407 accounting of the contribution of deep horizons in the case of perennial plants.

\section{Conclusions}

411 This work demonstrated that the $\delta^{13} \mathrm{C}$ values of grapes can be considered as a simple and 412 inexpensive surrogate for determining SAWC in rainfed vineyards. Moreover, the use of 413 proxies based on the perennial plant response, such as $\delta^{13} \mathrm{C}$, provides first order information 414 for comparison with theoretical SAWC, especially for the analysis of the contribution of deep 415 horizons. Successive monitored years, with the means of each annual $\delta^{13} \mathrm{C}$, combined 416 climatic variability and intrinsic $\delta^{13} \mathrm{C}$ variations. The relations did not change for the sites with 417 extreme SAWC, high or low. Conversely, the $\delta^{13} \mathrm{C}$ means for the sites with medium SAWC 418 moderated the interannual variability. This integrated relationship between the $\delta^{13} \mathrm{C}$ means 419 and SAWC was successfully tested for 8 independent sites. However, specific years without 420 sufficient soil water recharge are not appropriate for the use of a SAWC surrogate. Finally, 421 extensions of this study to other agro-systems are required to better define the potential area 422 of use of $\delta^{13} \mathrm{C}$.

\section{Acknowledgements}

This study was supported by the project RUEDESSOL financed by the french national research agency (ANR contract number 14 CE010011). The authors thank N. Saurin for the 
427 data and his help in Pech Rouge site. The authors thank particularly P. Tillard for the $\delta^{13} \mathrm{C}$ 428 analysis, J.L. Belotti for his help in soil analysis and D. Fages for the field sampling.

References

Al Majou, H., Bruand, A., Duval, O., Le Bas, C., Vautier, A., 2008. Prediction of soil water retention properties after stratification by combining texture, bulk density and the type of horizon. Soil Use Manag. 24 (4): 383-391.

Araya, S.,Lyle, G., Lewis, M., Ostendorf, B., 2016. Phenologic metrics derived from MODIS NDVI as indicators for Plant Available Water-holding Capacity. Ecol. Indic. 60: 12631272

Blake, G.R., Hartge, K.H., 1986. Bulk density. In: Klute, A., Ed., Methods of Soil Analysis, Part 1-Physical and Mineralogical Methods, 2nd Edition, Agronomy Monograph 9, American Society of Agronomy-Soil Science Society of America, Madison, 363-382. under severe drought: a review of ecophysiological responses, adaptation processes and long-term consequences. Ann. For. Sci. 63(6): 625-644.

Brisson, N., Mary, B., Ripoche, D., Jeuffroy, M.H., Ruget, F., Nicoullaud, B., Gate, P.,Devienne-Barret, F., Antonioletti, R., Durr, C., Richard, G., Beaudoin, G., Recous, S.,

446 Tayot, X., Plenet, D., Cellier, P., Machet, J.M., Meynard, J.M., Delécolle, R., 1998. STICS: a 447 generic model for the simulation of crops and their water and nitrogen balances. I. Theory 448 and parameterization applied to wheat and corn. Agronomie 18(5-6): 311-346. 
Costantini, E.A.C., Pellegrini, S., Bucelli, P., Barbetti, R., Campagnolo, S., Storchi, P.,

453

Magini, S., Perria, R., 2010. Mapping suitability for Sangiovese wine by means of delta C-13 and geophysical sensors in soils with moderate salinity. Eur. J. Agron. 33(3): 208-217.

de Souza, C.R., Maroco, J.P., dos Santos, T.P., Rodrigues, M.L., Lopes, C.M., Pereira, J.S. , Chaves, M.M., 2005. Impact of deficit irrigation on water use efficiency and carbon isotope composition $\left(\delta^{13} \mathrm{C}\right)$ of field-grown grapevines under Mediterranean climate. J. Exp. Bot. 56 (418): 2163-2172.

Dobarco, M.R., Cousin, I., Le Bas, C., Martin, M.P., 2019. Pedotransfer functions for predicting available water capacity in French soils, their applicability domain and associated uncertainty. Geoderma 336: 81-95.

Dominati, E., Mackay, A., Green, S., Patterson, M., 2014. A soil change-based methodology for the quantification and valuation of ecosystem services from agroecosystems: A case study of pastoral agriculture in New Zealand. Ecol. Econ. 100: 119-129.

FAO, 2006. Guidelines for soil description. Fourth edition. FAO, Rome

Farquhar, G.D., Ehleringer, J.R., Hubick, K.T., 1989. Carbon isotope discrimination and photosynthesis. Annu. Rev. Plant Physiol. Plant Molec. Biol. 40: 503-537.

Gaudillere, J.P., Van Leeuwen, C., Ollat, N., 2002. Carbon isotope composition of sugars in grapevine, an integrated indicator of vineyard water status. J. Exp. Bot. 53(369): 757-763.

Gomez-Alonso, S., Garcia-Romero, E., 2010. Effect of irrigation and variety on oxygen $\left(\delta^{18} \mathrm{O}\right)$ and carbon $\left(\delta^{13} \mathrm{C}\right)$ stable isotope composition of grapes cultivated in a warm climate. Aust. J. Grape Wine Res. 16(2): 283-289.

Guix-Herard, N., Voltz, M., Trambouze, W., Garnier, F., Gaudillere, J.P., Lagacherie, P., 2007. Influence of watertable depths on the variation of grapevine water status at the landscape scale. Eur. J. Agron. 27(2-4): 187-196. 
Herrero-Langreo, A., Tisseyre, B., Goutouly, J.P., Scholasch, T., Van Leeuwen, C.,

2013. Mapping Grapevine (Vitis vinifera L.) Water Status during the Season Using Carbon Isotope Ratio $\left(\delta^{13} \mathrm{C}\right)$ as Ancillary Data. Am. J. Enol. Vitic. 64(3): 307-315.

IUSS Working Group WRB, 2015. World reference base for soil resources 2014, update 2015. World Soil Resources Reports No. 106. FAO, Rome.

Klute, A., 1986. Water retention: Laboratory methods. In: Klute, A., Ed., Methods of Soil Analysis, Part 1-Physical and Mineralogical Methods, 2nd Edition, Agronomy Monograph 9, American Society of Agronomy-Soil Science Society of America, Madison, $635-662$.

Lebourgeois, F., Breda, N., Ulrich, E., Granier, A., 2005. Climate-tree-growth relationships of European beech (Fagus sylvatica L.) in the French Permanent Plot Network (RENECOFOR). Trees-Struct. Funct. 19(4): 385-401.

Leenaars, J.G.B., Claessens, L., Heuvelink, G.B.M., Hengla, T., Gonzalez, M.R., van Bussel, L.G.J., Guilpart, N., Yang, H.S., Cassman, K.G., 2018. Mapping rootable depth and root zone plant-available water holding capacity of the soil of sub-Saharan Africa. Geoderma 324: $18-36$.

McBratney, A.B., Santos, M.L.M., Minasny, B., 2003. On digital soil mapping. Geoderma 117(1-2) : 3-52.

Merah, O., Deleens, E, Monneveux, P., 2001. Relationships between carbon isotope discrimination, dry matter production, and harvest index in durum wheat. J. Plant Physiol. 158(6): 723-729.

Pellegrino, A., Lebon, E., Voltz, M., Wery, J., 2004. Relationships between plant and soil water status in vine (Vitis vinifera L.). Plant and Soil 266(1-2): 129-142.

Rawls, W.J., Brakensiek, D.L., Saxton, K.E., 1982. Estimation of soil water retention properties. Trans. ASAE 25: 1316-1320. 

ratio of whole berries as an estimator of plant water status in grapevine (Vitis vinifera L.) cv. 503 'Tempranillo'. Sci. Hortic. 146: 7-13. measurement of the natural abundance of stable isotopes in viticulture: a review. Aust. J. Grape Wine Res. 21(2): 157-161.

Taylor, J. A., Jacob, F., Galleguillos, M., Prevot, L., Guix, N., Lagacherie, P., 2013. The utility of remotely-sensed vegetative and terrain covariates at different spatial resolutions in modelling soil and watertable depth (for digital soil mapping). Geoderma 193: 83-93. of rock fragments to the available water content of stony soils: Proposition of new pedotransfer functions. Geoderma 165(1):40-49.

van Leeuwen, C., Gaudillere, J.P., Tregoat, O., 2001. The assessment of vine water uptake conditions by 13C/12C discrimination in grape sugar. J. Int. Sci. Vigne Vin. 35 (4): 195-205.

van Leeuwen, C., Tregoat, O., Chone, X., Bois, B., Pernet, D., Gaudillere, J.P., 2009.

517 Vine water status is a key factor in grape ripening and vintage quality for red Bordeaux wine.

518 How can it be assessed for vineyard management purposes ? J. Int. Sci. Vigne Vin. 43 (3): 519 121-134.

van Leeuwen, C., Roby, J.P., de Resseguier, L., 2018. Soil-related terroir factors: a 521 review. Oeno one 52(2): 173-188.

Veihmayer, F.J., Hendrickson, A.H., 1949. Methods of measuring field capacity and 523 pemanent wilting percentage of soils. Soil Sci. 68: 75-94.

Warren, C.R., McGrath, J.F., Adams, M.A., 2001. Water availability and carbon isotope discrimination in conifers. Oecologia 127(4): 476-486. 


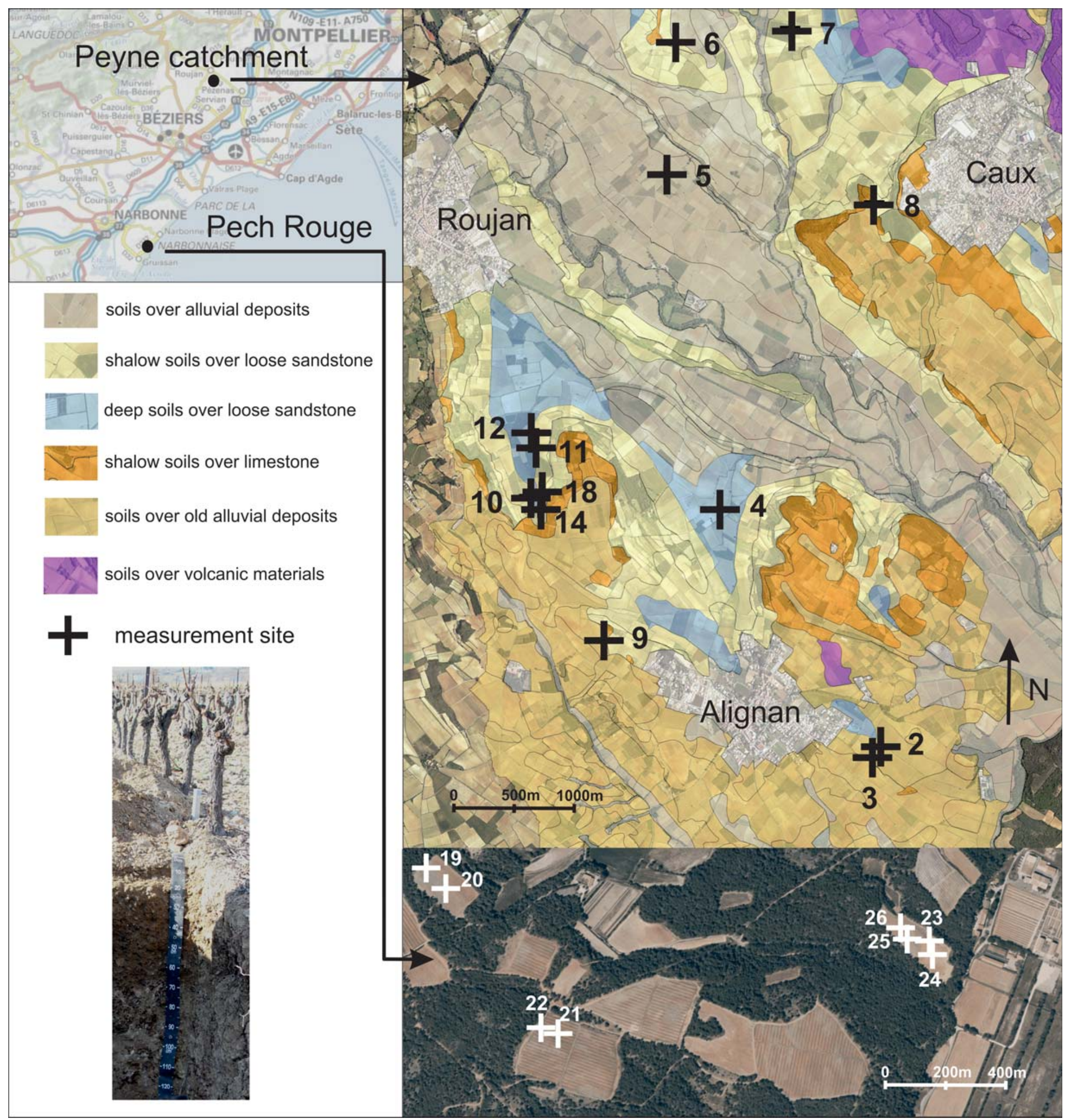


growth and ripening (april-aug)

$\checkmark$ before bud break (sept - march)

700

600

500

400

300

200

100

0

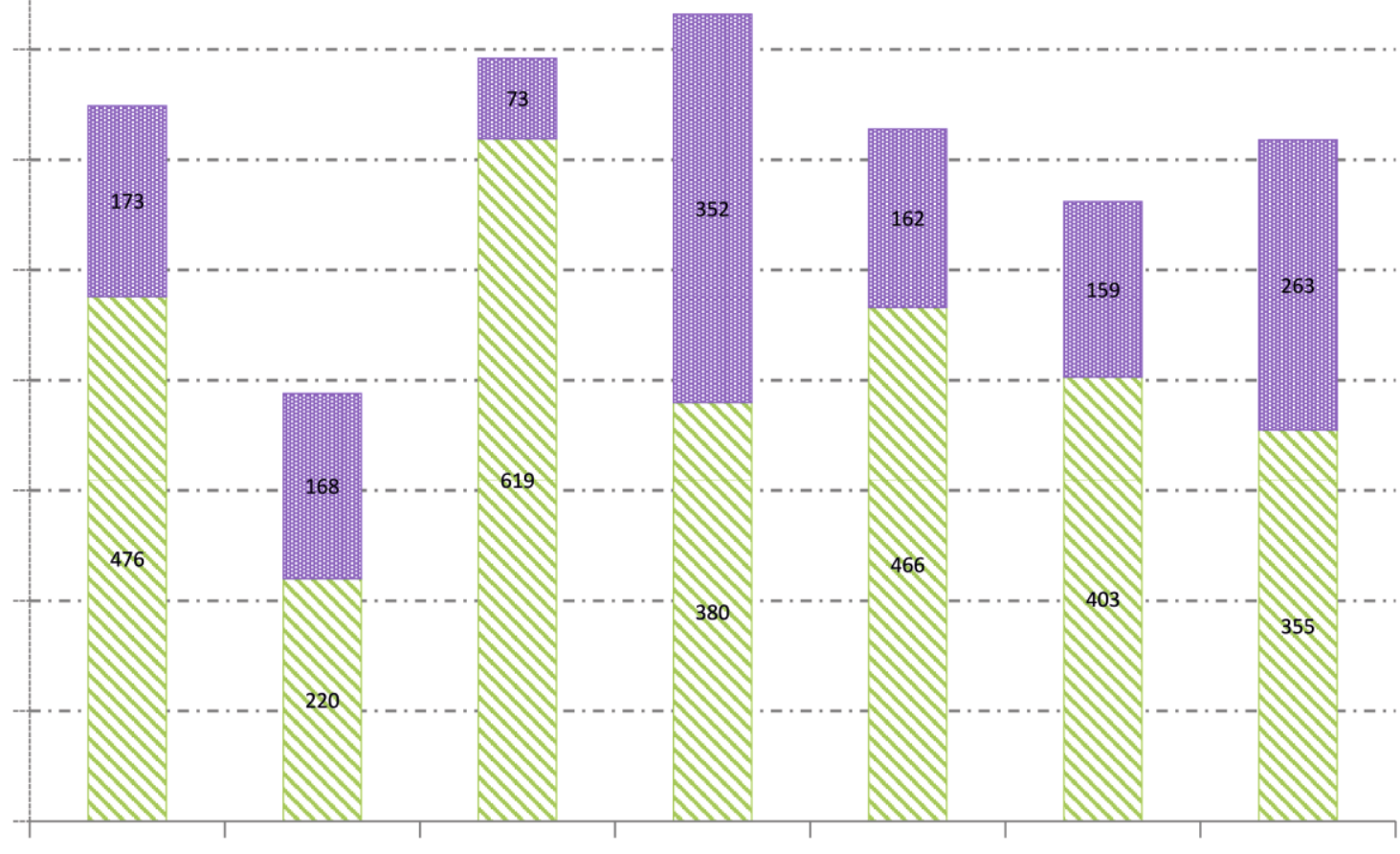

$2015 \quad 2016 \quad 2017$

2018

mean

mean 2018

(25y.) (25y.)

Peyne catchment

Pech Rouge 

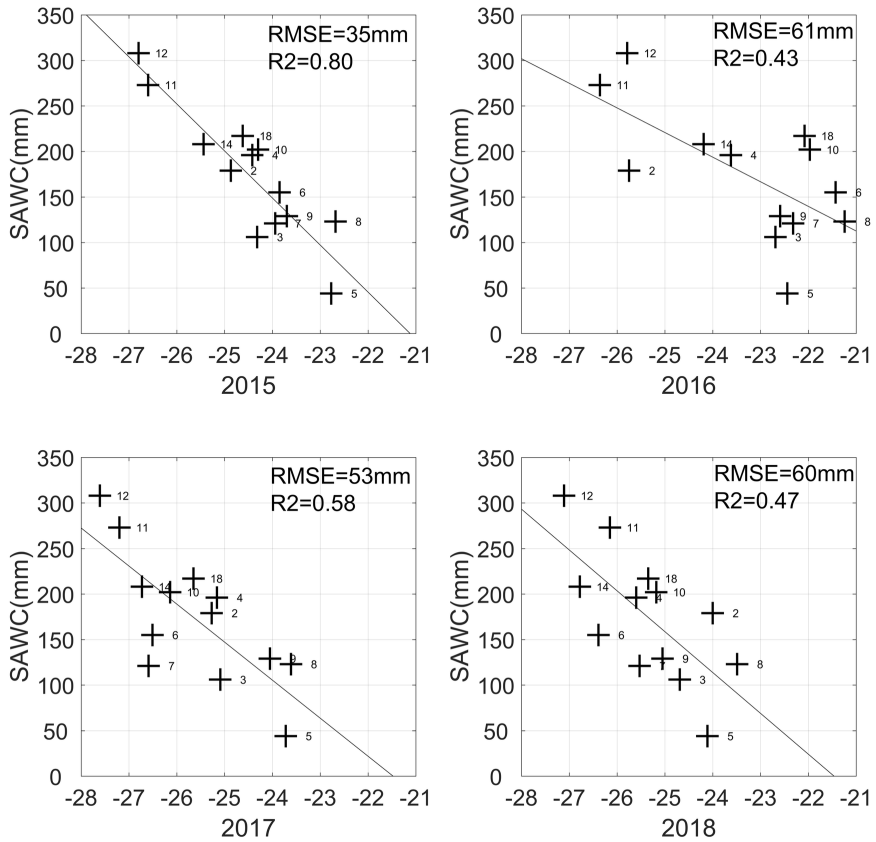

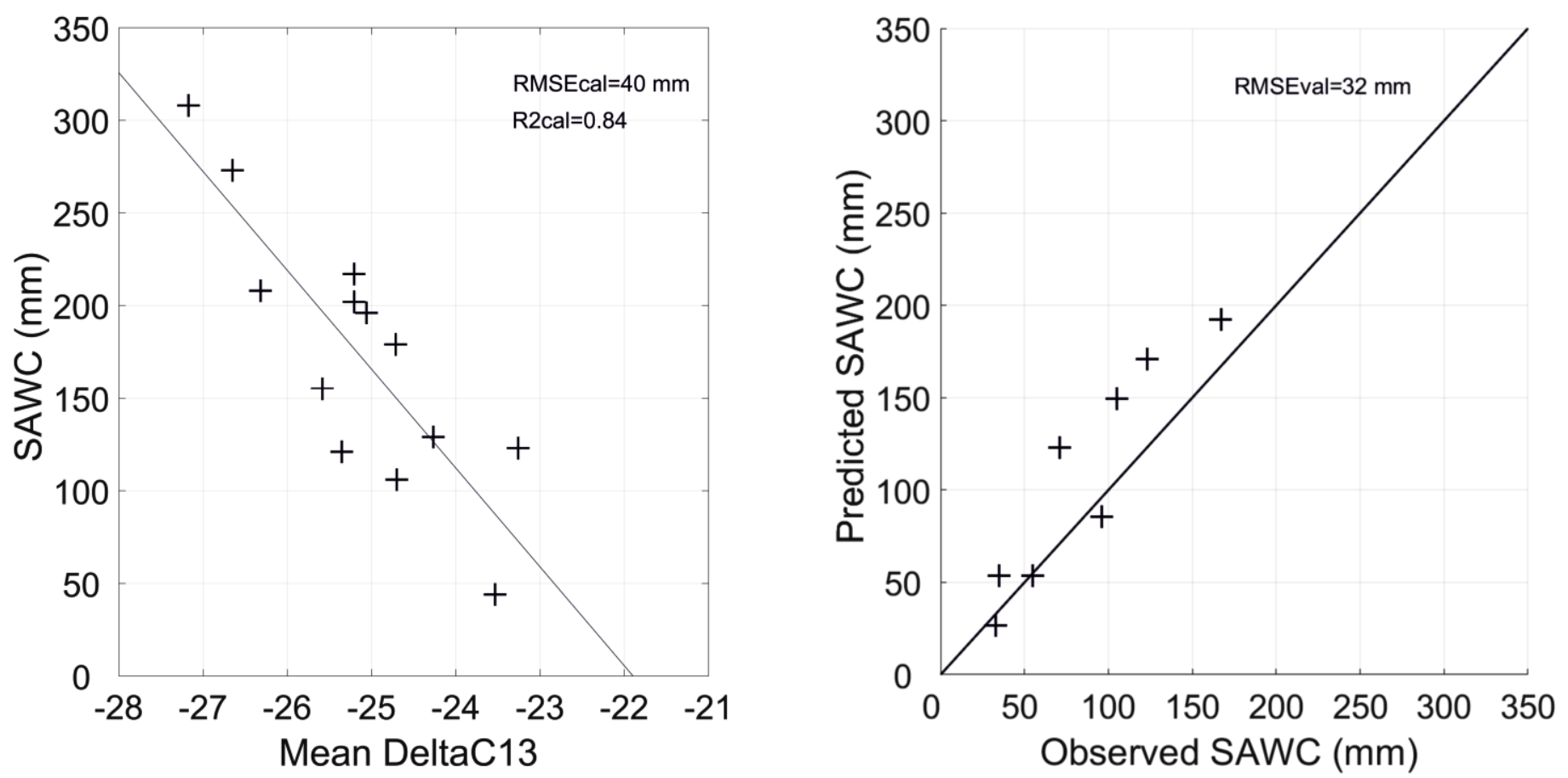
Table1: The Peyne and Pech Rouge datasets

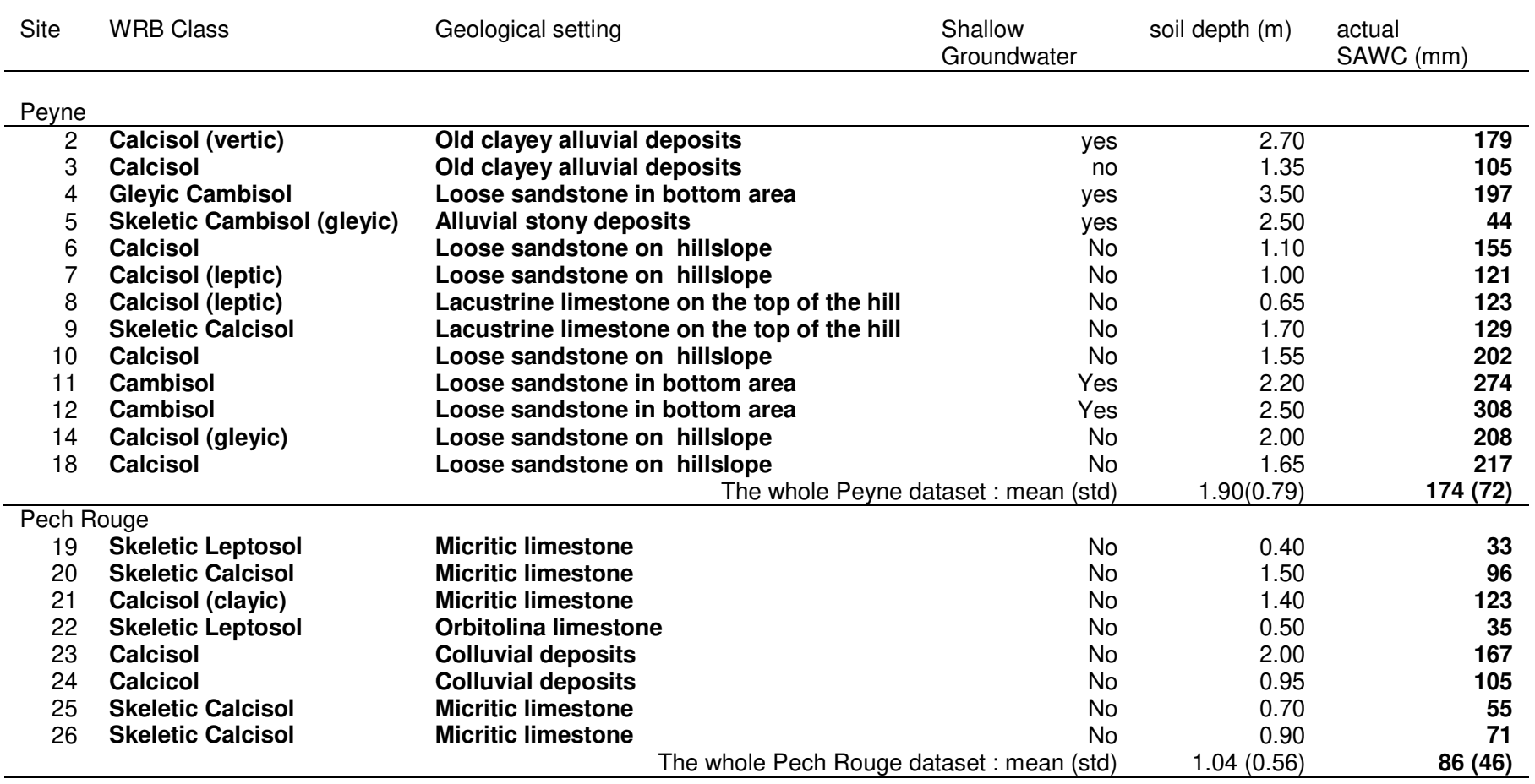


Table 2 : The whole $\Delta \mathrm{C} 13$ results during the 4 years

\begin{tabular}{llllll}
$\Delta \mathrm{C} 13$ & \multicolumn{2}{l}{ Peyne Catchment } & & Pech Rouge \\
\hline year & 2015 & 2016 & 2017 & 2018 & 2018 \\
Mean & $-24.49 \mathrm{a}$ & $-23.27 \mathrm{~b}$ & $-25.64 \mathrm{c}$ & $-25.34 \mathrm{ac}$ & $-23.89 \mathrm{ab}$ \\
Std & 1.24 & 1.73 & 1.30 & 1.09 & 1.26 \\
RStd & 5 & 7 & 5 & 4 & 5 \\
Min & -26.80 & -26.36 & -27.61 & -27.11 & -25.50 \\
Max & -22.68 & -21.24 & -23.61 & -23.49 & -22.2 \\
N & 13 & 13 & 13 & 13 & 8
\end{tabular}

Differents letters denote statistically significant differences between means (ANOVA and Tukey's HSD based on the Student distribution, at $\mathrm{P}<0.01$ ) 